\title{
QUANTIFICATION OF EXEMESTANE ACCUMULATION DURING MICROBIAL BIOCONVERSION BY TLC IMAGE ANALYSIS
}

\author{
PRACHI PATIL1 ${ }^{*}$, RAJESH SHARMA1, TUSHAR BANERJEE2, SHRIDHAR PATIL²
}

${ }^{1}$ School of Pharmacy, Devi Ahilya University, Indore, India, ${ }^{2}$ School of Life Sciences, Devi Ahilya University, Indore 452001, India Email: prachipatil.2607@gmail.com

Received: 19 Apr 2017 Revised and Accepted: 19 Jun 2017

\section{ABSTRACT}

Objective: The present study was aimed at developing a rapid, cost effective and accurate method for quantification of exemestane using thin layer chromatography (TLC) separation followed by image analysis and to test it for monitoring the accumulation of exemestane during microbial bioconversion.

Methods: After microbial bioconversion and TLC separation of products formed, exemestane was quantified using ImageQuant TL v2003 image analysis software and the results were compared with high performance liquid chromatography (HPLC) analysis.

Results: The percentage error between TLC and HPLC analyses was ranged from (-) 5.18 to (+) 5.51. Bacterial strains Arthrobacter simplex IAM 1660, Nocardia sp. MTCC 1534, Pseudomonas putida MTCC 1194 and Rhodococcus rhodochorus MTCC 291 respectively yielded 79.7 (72 h), 63.9 (72 h), $69.8(96 \mathrm{~h})$ and $83.2(96 \mathrm{~h})$ mole percent bioconversion of 6-methylene androstenedione to exemestane.

Conclusion: Rhodococcus rhodochorus MTCC 291 was found to be the most suitable organism for the bioconversion and may be used to develop an eco-friendly route to replace chemical synthesis that eliminates the use of toxic chemicals and side products.

Keywords: TLC image analysis, 6-Methylene androstenedione, C-1(2)-Dehydrogenation, Exemestane, Rhodococcus rhodochorus MTCC 291

(C) 2017 The Authors. Published by Innovare Academic Sciences Pvt Ltd. This is an open access article under the CC BY license (http://creativecommons.org/licenses/by/4.0/) DOI: http://dx.doi.org/10.22159/ijpps.2017v9i8.19201

\section{INTRODUCTION}

Exemestane, a third generation steroidal aromatase inhibitor, is a widely used drug for the treatment of breast cancer in postmenopausal patients [1-3]. The synthesis of exemestane is based on chemical conversion of a variety of steroid substrates [4-9]. However, the chemical synthesis involves multiple steps and use of hazardous chemicals during the final step of C-1(2)dehydrogenation, making it undesirable. Alternative route of microbial C-1(2)-dehydrogenation of 6-methylene androstenedione (6-MeAD) to yield exemestane has been developed and patented [10, 11]. The later is an eco-friendly route that eliminates the use of toxic chemicals and side products formed during chemical synthesis. Recently, Patil et al. $[12,13]$ have reported C-1(2)-dehydrogenation of 6-MeAD to exemestane by of several bacterial strains.

Number of methods have been employed for quantification of exemestane in samples of human urine by gas chromatography/mass spectrometry [14-15] and liquid chromatography/tandem mass spectrometry [16], in human plasma by LC-MSMS [17], in various pharmaceutical dosage forms and stability testing by HPTLC, HPLC and RP-HPLC [18-22]. All these methods are time-consuming and involve sophisticated instrumentation.

Thin-layer chromatography (TLC) is an important tool for qualitative analysis of various analytes because of its inherent advantages. Many samples can be analyzed simultaneously and quickly by TLC. It does not require UV activity, paramagnetic properties or volatility as mandatory for LC, NMR and GC quantification respectively, making TLC one of the most powerful and general analytical tool. Detection limits of TLC are often low and quantitative densitometric methods are accurate.

Common office scanners are frequently used as densitometers for scanning stained TLC plates followed by processing the digital image by image analysis software [23-27]. Quantification of $\alpha$-tocopherol and ergocalciferol by TLC, scanning and processing of the chromatogram with video densitometry software has also been reported [28].

C-1(2)-dehydrogenation of steroids is an important bioconversion reaction catalyzed by microorganisms. A number of bacterial genera have been reported to dehydrogenate various steroidal precursors to their C-1(2)-dehydrogenated products [29-32]. During laboratory, pilot and industrial fermentations; timely analysis of bioconversion product formed in the medium is crucial for terminating the fermentation for maximum yield of the product and requires a suitable method for qualitative and quantitative analysis of exemestane accumulated in the medium. Few reports based on quantification of steroid drug intermediates formed during bioconversion of soysterols are available [33-35]. However, quantification of exemestane during C-1(2)-dehydrogenation of 6MeAD has not been reported so far. The aim of present work was to develop a simple, accurate, cost effective and rapid method for monitoring this bioconversion using TLC separation followed by quantification of exemestane using image analysis software.

\section{MATERIALS AND METHODS}

\section{Thin layer chromatography}

TLC analysis was carried out in triplicate on a pre-coated silica gel plate (silica gel $60 \mathrm{~F}$ Merck, Darmstadt). The plate was activated at $100{ }^{\circ} \mathrm{C}$ for $10 \mathrm{~min}$, cooled and spotted with chloroform solutions containing 2, 3 and $4 \mu \mathrm{g}$ of authentic 6-MeAD synthesized in the laboratory as described earlier [12] and exemestane procured from Cipla Ltd., Mumbai, India. Similarly, the spots of known amount in different proportions of both compounds $(3+1,2+2$ and $1+3 \mu \mathrm{g}$ of exemestane and 6-MeAD respectively) were spotted in the centre of the same plate. The plate was developed in benzene: ethyl acetate (5:2). The spots were visualized by spraying the plate with $50 \%$ sulphuric acid followed by heating at $110^{\circ} \mathrm{C}$ for $5 \mathrm{~min}$.

Scanning, calibration and quantification by image analysis software

After cooling, the plate was scanned using HP Laser Jet (model M1005 MFP) office scanner. The compounds were quantified by using Image Quant TL v2003 image analysis software (Amersham Biosciences). This software converts the scanned digital image in grey scale, enables selection of the desired spot, determines the area and intensity of spots and averages the pixel values using area and profile-based tools. The calibration plots were prepared by loading 
three known concentrations of authentic samples and their mixtures in different proportions on the plate and quantities of individual compounds were calculated by referring the calibration plots and compared with concentrations obtained by HPLC analysis.

\section{Detection range and scanning error}

Chloroform solution containing $0.5,2$ and $3 \mu \mathrm{g}$ of each of $6-\mathrm{MeAD}$ and exemestane were spotted on TLC plate to determine the lower detection range. Similarly, 10, 20 and $30 \mu \mathrm{g}$ of each of these compounds were spotted on another plate to determine higher range of detection. Three plates of both ranges were developed and processed as described above to determine detection range and linearity. To determine the scanning error, each plate was scanned three times on an office scanner at 300,600 and 1,200 dpi resolution and the results were analyzed by image analysis software.

\section{HPLC quantification}

HPLC method described earlier [19] was used for quantification of exemestane simultaneously to assess validity of quantification by image analysis software. The specifications of JASCO (Model 1580) equipment were-column: ODS HYPERSIL $\mathrm{C}_{18}(250 \times 4.6 \mathrm{~mm})$, column temperature $45{ }^{\circ} \mathrm{C}$, detection wavelength- $245 \mathrm{~nm}$, mobile phase acetonitrile: water $(60: 40)$, flow rate $0.45 \mathrm{ml} / \mathrm{min}$ and total run time $20 \mathrm{~min}$. Chloroform solutions of $6-\mathrm{MeAD}$ and exemestane prepared for spotting on the TLC plate were injected with a fixed loop of $20 \mu$ l Rheodyne injector.

\section{Microorganisms}

Bacterial strains used in this study were procured from Microbial Type Culture Collection and Gene Bank (MTCC), Institute of Microbial Technology, India; Institute of Applied Microbiology (IAM), University of Tokyo, Japan and Northern Regional Research laboratory (NRRL), Agricultural Research Service, USA. All organisms were grown on nutrient agar slants and preserved at $4{ }^{\circ} \mathrm{C}$.

\section{Bioconversion, extraction and quantification of exemestane}

Bioconversion with each organism was carried out in triplicate flasks of $150 \mathrm{ml}$ capacity Erlenmeyer flasks. Pre-weighed $30 \mathrm{mg}$ of 6MeAD was transferred in a flask, dissolved in $0.5 \mathrm{ml}$ soybean oil and $30 \mathrm{ml}$ nutrient broth ( $\mathrm{pH}$ 7.2) was added to it with continuous stirring on a magnetic stirrer. After sterilization at $121^{\circ} \mathrm{C}$ for $15 \mathrm{~min}$, the flasks were inoculated aseptically with $1 \mathrm{ml}$ overnight cultures of bacterial strains grown in nutrient broth and the flasks were incubated at $32 \pm 2{ }^{\circ} \mathrm{C}$ on a gyratory incubator shaker $(200 \mathrm{rpm}, 1.5$ $\mathrm{cm}$ eccentric throw). Samples of the incubation medium were aseptically drawn for quantification after regular intervals of $24 \mathrm{~h}$, centrifuged and upper oil phase $(100 \mu \mathrm{l})$ was transferred in an eppendroff tube, thoroughly mixed with $1 \mathrm{ml}$ methanol on a cyclomixer and centrifuged at 10,000 rpm for $10 \mathrm{~min}$. The upper methanolic phase was dried over sodium sulphate and $10 \mu \mathrm{l}$ extract was spotted on TLC plate along with 1, 2 and $3 \mu \mathrm{g}$ exemestane for analysis as described above.

\section{RESULTS AND DISCUSSION}

\section{Detection range and scanning error}

The detection range of spots of exemestane was better than that of 6-MeAD at lower concentrations $(0.5-3.0 \mu \mathrm{g})$ used for image analysis. At higher concentrations $(10-30 \mu \mathrm{g})$, both compounds exhibited a linear relationship between the amounts and spot area with $\mathrm{r}^{2}$ values greater than +0.99 . The resolution used for scanning the plates (300-1,200 dpi) did not affect the relative intensities of spots and $r^{2}$ values obtained for linear relationship between spot area and concentration.

\section{Calibration, quantification and validation}

Depicts TLC chromatogram of standard concentrations of 6-MeAD, exemestane and mixtures of both in different proportions [A]. The spot area on the plate and concentrations of 6-MeAD and exemestane determined by image analysis software yielded a linear response for three point calibration. For both the compounds, $\mathrm{r}^{2}$ values were greater than +0.99 (fig. $1,[\mathrm{~B}$ and $\mathrm{C}]$, indicating the validity straight line equation obtained by software. Although the visual chromogenecity of spots of 6-MeAD was less than exemestane, both these compound could be quantified at concentrations as low as $1 \mu \mathrm{g}$. Using the image analysis, the amounts of $6-\mathrm{MeAD}$ and exemestane separated on TLC plate were in good agreement with the results obtained with HPLC (table 1). When compared with HPLC, the quantification by TLC image analysis showed percentage error within an acceptable limits of (-) 5.18 to (+) 5.51 for 6-MeAD and (-) 4.04 to (+) 3.04 for exemestane.

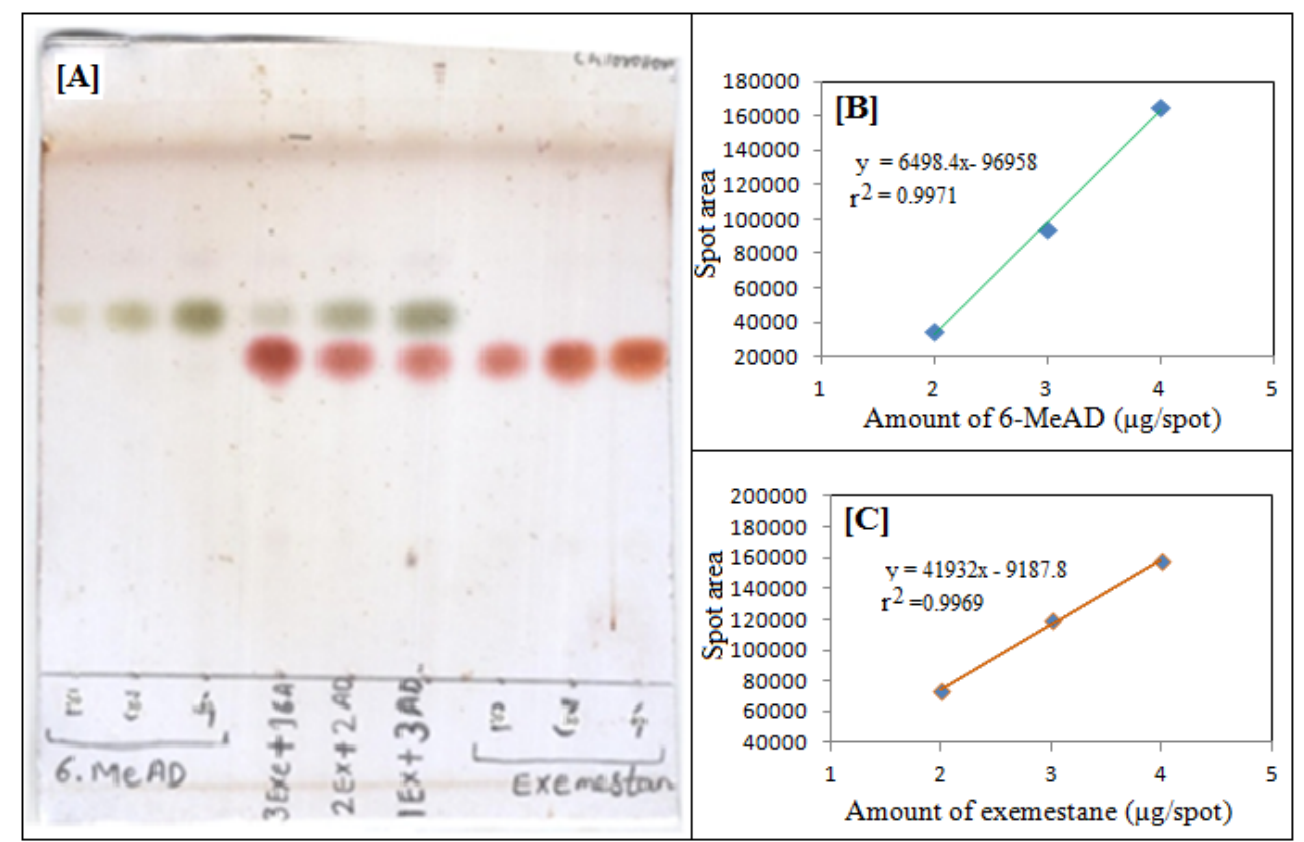

Fig. 1: TLC chromatogram of standard concentrations $(2,3$ and $4 \mu \mathrm{g})$ of $6-\mathrm{MeAD}$ (left), exemestane (right) and mixtures $(1+3,2+2$ and $3+1 \mu \mathrm{g}$ ) of these compounds respectively (center) $[\mathrm{A}]$ and response curves between spot area and concentration of 6-MeAD [B] and exemestane $[\mathrm{C}]$ obtained by image analysis software 
Table 1: Amounts of 6-MeAD and exemestane quantified by image analysis software and HPLC

\begin{tabular}{lllll}
\hline 6-MeAD & \multicolumn{3}{l}{ Exemestane } \\
\hline TLC $(\boldsymbol{\mu g})$ & HPLC $(\boldsymbol{\mu g})$ & Error $(\%)$ & TLC $(\boldsymbol{\mu g})$ & HPLC $(\boldsymbol{\mu g})$ \\
\hline $98.39 \pm 6.67$ & $103.76 \pm 8.69$ & -5.18 & $298.97 \pm 31.29$ & $311.56 \pm 23.87$ \\
$197.46 \pm 10.62$ & $206.46 \pm 6.87$ & -4.36 & $205.33 \pm 23.74$ & $197.12 \pm 18.25$ \\
$315.13 \pm 19.55$ & $298.67 \pm 23.22$ & 5.51 & $102.76 \pm 6.56$ & 4.04 \\
\hline
\end{tabular}

Data are Mean of triplicates \pm Standard deviation.

After confirmation of essential criteria for quantification including selectivity, linearity, limit of detection and repeatability, the validity of image analysis method was tested using some bacterial strains reported in the literature to dehydrogenate various steroidal precursors to their C-1(2)-dehydrogenated products. Exemestane accumulated in the fermentation broth during the bioconversion of 6-MeAD were estimated by HPLC as well as image analysis after separation of these compounds on TLC plate (fig. 2). It was observed that out of five strains selected for the study, three organisms accumulated exemestane at $48 \mathrm{~h}$ incubation period. At $48 \mathrm{~h}$, Arthrobacter simplex IAM 1660, Nocardia sp. MTCC 1534 and
Rhodococcus rhodochorus MTCC 291 yielded about 73.4, 55.9 and 16.4 mole percentage bioconversions respectively. Comamonas testosteroni NRRL 2611 failed to accumulate exemestane in the incubation medium throughout the course of fermentation. Except Comamonas testosteroni NRRL 2611, the bioconversion by other bacterial strains increased at $96 \mathrm{~h}$ incubation period and a maximum mol \% bioconversion was recorded in case of Rhodococcus rhodochorus MTCC 291. The percentage error between all estimations by image analysis and HPLC of 6-MeAD and exemestane was found to range between an acceptable experimental error of (-) 5.38 to (+) 4.71 (table 2).

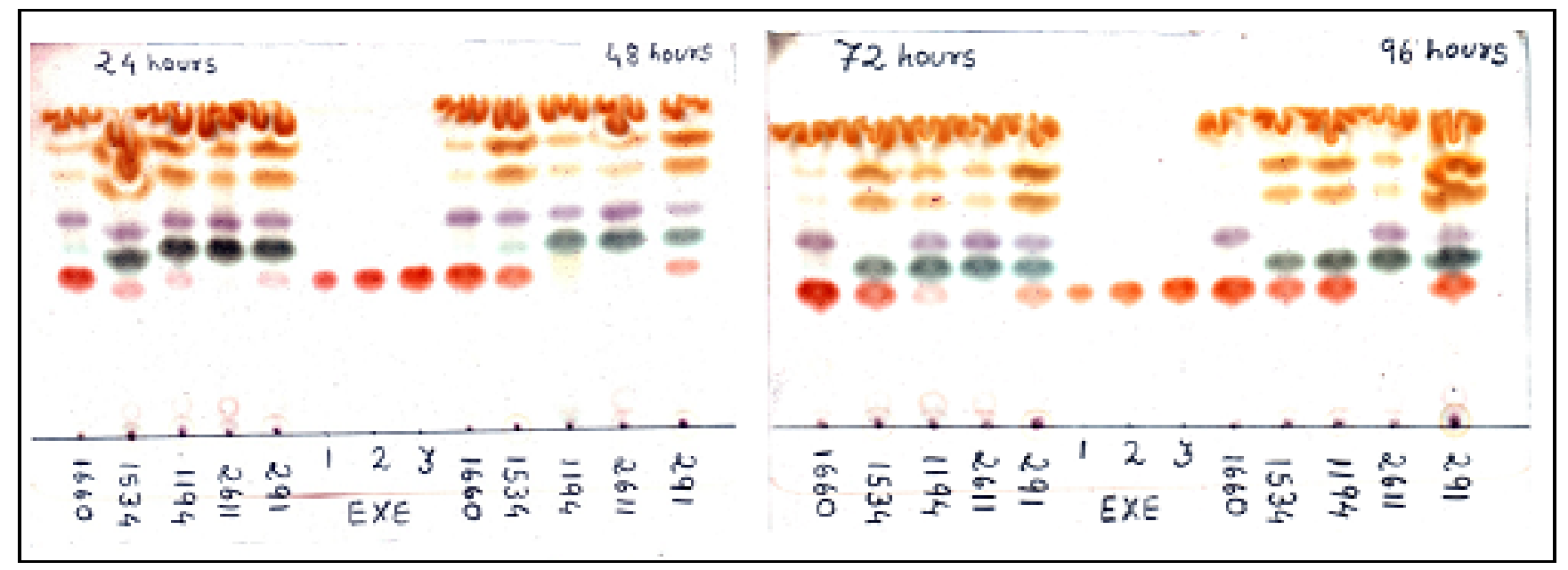

Fig. 2: TLC chromatogram of exemestane (red spot) accumulated in the fermentation broth during the bioconversion of 6-MeAD (greygreen spot) by microorganisms

Table 2: Mole percentage bioconversion of 6-MeAD to exemestane accumulated in fermentation broth by some bacterial strains and quantified by TLC using image analysis software and HPLC

\begin{tabular}{|c|c|c|c|c|c|c|c|c|c|c|c|c|}
\hline \multirow[t]{3}{*}{ Organism } & \multicolumn{12}{|c|}{ Mol \% bioconversion after incubation period \pm SD (h) } \\
\hline & \multicolumn{3}{|c|}{24} & \multicolumn{3}{|c|}{48} & \multicolumn{3}{|l|}{72} & \multicolumn{3}{|l|}{96} \\
\hline & TLC & HPLC & $\begin{array}{l}\text { Error } \\
(\%)\end{array}$ & TLC & HPLC & $\begin{array}{l}\text { Error } \\
\text { (\%) }\end{array}$ & TLC & HPLC & $\begin{array}{l}\text { Error } \\
(\%)\end{array}$ & TLC & HPLC & $\begin{array}{l}\text { Error } \\
\text { (\%) }\end{array}$ \\
\hline Arthrobacter simplex & 58.56 & 56.98 & 2.77 & 73.39 & 75.44 & -2.72 & 79.67 & 82.25 & -3.14 & 78.04 & 78.67 & -0.80 \\
\hline IAM 1660 & \pm 5.23 & \pm 4.18 & & \pm 7.76 & \pm 3.57 & & \pm 5.97 & \pm 4.92 & & \pm 8.98 & \pm 5.57 & \\
\hline Nocardia sp. & 11.23 & 10.95 & 2.56 & 55.89 & 56.73 & -1.48 & 63.93 & 61.27 & 4.34 & 61.67 & 60.45 & 2.02 \\
\hline MTCC 1534 & \pm 1.93 & \pm 2.04 & & \pm 6.33 & \pm 3.05 & & \pm 4.88 & \pm 0.97 & & \pm 4.54 & \pm 4.38 & \\
\hline Pseudomonas putida & 5.09 & 4.87 & 4.52 & 4.02 & 3.92 & 2.55 & 7.81 & 8.23 & -5.10 & 69.82 & 68.23 & 2.33 \\
\hline MTCC 1194 & \pm 0.32 & \pm 0.49 & & \pm 0.70 & \pm 0.12 & & \pm 0.56 & \pm 0.41 & & \pm 3.90 & \pm 5.49 & \\
\hline Comamonas testosteroni & 0.04 & 0.00 & ----- & 0.23 & 0.00 & ----- & 0.13 & 0.00 & ---- & 0.09 & 0.00 & ---- \\
\hline NRRL 2611 & \pm 0.02 & & & \pm 0.08 & & & \pm 0.04 & & & \pm 0.06 & & \\
\hline Rhodococcus rhodochorus & 6.68 & 7.06 & -5.38 & 16.45 & 15.71 & 4.71 & 21.79 & 22.82 & -4.51 & 83.16 & 81.09 & 2.55 \\
\hline MTCC 291 & \pm 0.23 & \pm 0.22 & & \pm 2.12 & \pm 0.92 & & \pm 1.37 & \pm 1.67 & & \pm 13.39 & \pm 6.90 & \\
\hline
\end{tabular}

Data are mean of triplicates \pm Standard deviation

For better understanding and timely termination, a rapid method for monitoring the progress of fermentation is a prerequisite. TLC image analysis based methods for quantification of steroid drug intermediates formed during bioconversion of soysterols and phytosterols have been described for monitoring the fermentation processes [34-36]. The TLC separation followed by image analysis software presented here enabled fairly accurate and rapid quantification of exemestane in a short time. Moreover, this method is superior to other available methods based on spectrophotometry, $\mathrm{LC}$, and GC as the cost of solvents and instrumentation is minimum. 
It also enables simultaneous processing of multiple samples on single TLC plate along with standards, leading to better analytical precision. No prior treatment of solvents like filtration or degassing is required. There is no possibility of interference from the previous analysis, as fresh stationary and mobile phases can be prepared for each analysis. The method proved fairly accurate when applied to authentic compounds and to samples of fermentation medium.

The present work revealed the capacity of C-1(2)-dehydrogenation of Nocardia sp. MTCC 1534, Pseudomonas putida MTCC 1194, and Rhodococcus rhodochorus MTCC 291 for the bioconversion of 6-MeD to exemestane, which has not been reported so far. Besides developing a rapid, cost effective and accurate method to quantify exemestane, it reports the suitability of Rhodococcus rhodochorus MTCC 291 for this bioconversion to develop an eco-friendly route that eliminates the use of toxic chemicals and side products formed during chemical synthesis of this widely used drug. Also the TLC image analysis method presented in this study may be standardized and adopted to quantify exemestane in various body fluids like human urine and plasma.

\section{CONCLUSION}

A rapid, sensitive and cost effective method for quantification of exemestane was developed and tested to follow the progress of C1(2)-dehydrogenation of 6-MeAD to exemestane by microorganisms. This is the first report on quantitation of exemestane using image analysis software. The method may be used to quantify exemestane in blood/urine samples of breast cancer patients without the requirement of sophisticated instrumentation. Furthermore, three unreported bacterial strains were identified to catalyze C-1(2)dehydrogenation of 6-MeAD to yield exemestane.

\section{ACKNOWLEDGEMENT}

One of the authors (SP) thanks the University Grants Commission, New Delhi for financial assistance.

\section{AUTHORS CONTRIBUTION}

1. PP-Planned the experimental setup and performed wet lab work.

2. RS-Suggested modifications in the experimental setup and monitored the progress of work.

3. TB-Image analysis of TLC plates was carried out with software.

4. SP-Correlated the experimental findings with results of other workers.

\section{CONFLICT OF INTERESTS}

\section{Declared none}

\section{REFERENCES}

1. Benedict Paul C, Sudandiradoss C. Aromatase inhibitors-types and advantages. Int J Pharm Pharm Sci 2016;8:1-7.

2. Goss PE, Ingle JN, Alés-Martínez JE, Cheung AM, Chlebowski RT, Wactawski-Wende J, et al. Exemestane for breast-cancer prevention in postmenopausal women. $\mathrm{N}$ Engl J Med 2011;364:2381-91.

3. Trédan O, Follana P, Moullet I, Cropet C, et al. A phase III trial of exemestane plus bevacizumab maintenance therapy in patients with metastatic breast cancer after first-line taxane and bevacizumab: a GINECO group study. Ann Oncol 2016;27:1020-9.

4. Agarwal VK, Singh MK, Patel AM. Process for preparing aromatase inhibitor exemestane. US Patent: 8288571; 2012.

5. Buzzetti F, Barbugian N, Lombardi P. 6-substituted androsta1,4-diene-3,17-dione. US Patent: 4808616; 1989.

6. Longo A, Lombardi P. Process for the preparation of methylene derivatives of androsta-1, 4-diene-3, 17-dione. US Patent: 4876045; 1989.

7. Kunnen K, Stehle NW, Weis SW, Pascone JM. Exemestane and its intermediates and methods of making the same. US Patent: 8183401; 2012.

8. Agarwal VK, Singh MK, Patel AM. Process for preparing aromatase inhibitor exemestane. PCT Patent: WO 2009/093262A2; 2009.
9. Marcos-Escribano A, Bermejo FA, Bonde-Larsen AL, Retuerto JI, Sierra IH. 1, 2-Dehydrogenation of steroidal 6-methylen derivatives. Synthesis of exemestane. Tetrahedron 2009;65:7587-90.

10. Sukhodolskaya GV, Fokina VV, Savinova TS, Shutov AA. Combined chemical and microbiological synthesis of exemestane from sitosterol. J Biotechnol 2010;30;150:89.

11. Savinova TS, Lukashev NV, Sukhodolskaya GV, Donova MV, et al. Method for obtaining 6-methyleneandrost-4-ene-3, 17-dione and obtaining of 6-methylene androsta-1, 4-diene-3, 17-dione (exemestane) from 6-methyleneandrost-4-ene-3, 17-dione thereof. Patent: RU2425052; 2011.

12. Patil P, Sharma R, Banerjee T, Patil S. Substrate carriers for C-1dehydrogenation of 6-methylene androstenedione to exemestane by growing and immobilized Arthrobacter simplex NCIM 2449. Asian J Pharm Clin Res 2017;10:392-6.

13. Patil P, Sharma R, Banerjee T, Patil S. The C-1-dehydrogenation of 6-methylene androstenedione to exemestane, an aromatase inhibitor used for the treatment of breast cancer. Int J Appl Biol Pharm Technol 2017;8:107-11.

14. Mareck U, Geyer H, Guddat S, Haenelt N. Identification of the aromatase inhibitors anastrozole and exemestane in human urine using liquid chromatography/tandem mass spectrometry. Rapid Commun Mass Spectrom 2006;20:1954-62.

15. Ksycińska H, Buś-Kwaśnik K, Szlagowska A, Rudzki PJ. Development and validation of a sensitive liquid chromatography/tandem mass spectrometry method for the determination of exemestane in human plasma. J Chromatogra B 2011;879:1905-10.

16. Cavalcanti GD, Garrido BC, Leal FD, Padilha MC. Analysis of exemestane and $17 \beta$-hydroxyexemestane in human urine by gas chromatography/mass spectrometry: development and validation of a method using MO-TMS derivatives. Rapid Commun Mass Spectrom 2010;24:3297-302.

17. Cenacchi V, Baratte S, Cicioni P, Frigerio E. LC-MS-MS determination of exemestane in human plasma with heated nebulizer interface following solid-phase extraction in the 96 well plate format. J Biomed Anal 2000;22:451-60.

18. Mane MB, Sangshetti JN, Wavhal PJ, Wakte PS. Determination of exemestane in bulk and pharmaceutical dosage form by HPTLC. Arabian J Chem 2014; 7:504-8.

19. Yavuz B, Bilensoy E, Şumnu M. Analytical method validation for HPLC assay of oral anticancer drug exemestane. J Pharm Sci 2007;32:15-22.

20. Kumar UK, Vinatha B, Sunitha P, Sushma GS. Method development and method validation of exemestane in bulk and pharmaceutical dosage form by RP-HPLC technique. J Sci Res Pharm 2012;1:115-7.

21. Mukthinuthalapati MA, Bukkapatnam V. A novel validated stability-indicating RP-HPLC method for the determination of exemestane (steroidal aromatase inhibitor). J Bioequivalence Bioavailability 2015;7:288-92.

22. Konda B, Tiwari RN, Fegade H. Development and validation of stability indicating method for the determination of exemestane by reverse phase high performance liquid chromatography. J Chromatogra Sci 2011;49:634-9.

23. Cimpoiu C, Hosu A, Hodisan S. Analysis of some steroids by thin-layer chromatography using optimum mobile phases. J Pharm Biomed Anal 2006;41:633-7.

24. Johnsson R, Träff G, Sundén M, Ellervik U. Evaluation of quantitative thin layer chromatography using staining reagents. J Chromatogr A 2007;1164:298-305.

25. Poole CF. Planar chromatography at the turn of the century. J Chromatogra A 1999;856:399-427.

26. Poole CF. Thin-layer chromatography: challenges and opportunities. J Chromatogra A 2003;1000:963-84.

27. Gerasimov AV. Use of the software processing of scanned chromatogram images in quantitative planar chromatography. J Anal Chem 2004;59:348-53.

28. Borodina EV, Kitaeva TA, Safonova EF, Selemenev VF. Determination of $\alpha$-tocopherol and ergocalciferol by thin-layer chromatography. J Anal Chem 2007;62:1064-8.

29. Jethva J, Pawar K, Shah J, Vyas J. Bioconversion of 11- $\beta, 17-\alpha$, 21-trihydroxy-4-pregnene-3, 20-dione, 21-o-succinate by 
actively growing culture of Pseudomonas putida MTCC 1259. Int J Appl Biol Pharm Technol 2011;3:167-72.

30. De las Heras LF, Van der Geize R, Drzyzga 0, Perera J. Molecular characterization of three 3-ketosteroid- $\Delta$ 1-dehydrogenase isoenzymes of Rhodococcus ruber strain Chol-4. J Steroid Biochem Mol Biol 2012;1323:271-81.

31. Horinouchi M, Hayashi T, Yamamoto T, Kudo T. A new bacterial steroid degradation gene cluster in Comamonas testosteroni TA441 which consists of aromatic-compound degradation genes for seco-steroids and 3-ketosteroid dehydrogenase genes. Appl Environ Microb 2003;69:4421-30.

32. Kominek LA, Wolf HJ, Process for preparing 1, 2-dehydro steroids. US Patent: 4524134; 1985.

33. Gulla V, Banerjee T, Patil S. Quantitative TLC analysis of steroid drug intermediates formed during bioconversion of soysterols. Chromatographia 2008;68:663-7.
34. Pendharkar GB, Anjum SD, Patil S. Enhanced biotransformation of phytosterols, a byproduct of soybean refineries to a key intermediate used for synthesis of steroidal drugs. Asian J Pharm Clin Res 2014; 7:178-80.

35. Pendharkar GB, Awadhiya PK, Banerjee T, Patil S. Effect of substrate concentration on the bioconversion of phytosterols to androst-4-ene-3,17-dione (AD) by Mycobacterium fortuitum subsp. fortuitum NCIM 5239. Int J Pharm Res Dev 2014;6:24-32.

\section{How to cite this article}

- $\quad$ Prachi Patil, Rajesh Sharma, Tushar Banerjee, Shridhar Patil. Quantification of exemestane accumulation during microbial bioconversion by tlc image analysis. Int J Pharm Pharm Sci 2017;9(8): 105-109 